29

\section{VENTILATION AND PERFUSION ABNORMALITIES IN INFANTS WITH BRONCHOPULMONARY DYSPLASIA}

M. Kjellberg ${ }^{1}$, K. Björkman², A.S. Crespo ${ }^{3}$, M. Katz-Salomon ${ }^{1}$, B. Jonsson ${ }^{1}$

${ }^{1}$ Departement of Woman and Child health, ${ }^{2}$ Departement of Anestesiology, Karolinska Institute, Karolinska University Hospital, ${ }^{3}$ Departement of Nuclear Medicine, Karolinska Institutet and University Hospital, Stockholm, Sweden

Introduction and aims: BPD is the most common chronic lung disease in infancy causing substantional morbidity. It is currently graded at 36 weeks according to the need for supplemental oxygen and/or positive pressure support ${ }^{1}$.

Our aim was to investigat whether the increased oxygen need was related to ventilation/perfusion abnormalities using single photon computed tomography (SPECT) and if abnormalities increased relative to an increasing severity score.

Method: We used quantitative SPECT technique to study the regional ventilation/perfusion matching. Perfusion was mapped with $99 \mathrm{mTc}$-albumin and ventilation by inhalation of an $99 \mathrm{~m}$-tc marked aerosol. 29 infants with BPD born at Karolinska University hospital were investigated at 36 weeks corrected age.

\section{Results:}

\begin{tabular}{|l|l|l|l|}
\hline $\begin{array}{l}\text { Lung within } \\
\text { normal V/Q } \\
\text { ratio 0,6-1,4 }\end{array}$ & Mild (9) & $\begin{array}{l}\text { Moderate } \\
(11)\end{array}$ & Severe (9) \\
\hline $\begin{array}{l}\text { Left lung } \\
(\%)\end{array}$ & 49 & 45 & 42 \\
\hline $\begin{array}{l}\text { Right lung } \\
(\%)\end{array}$ & 51 & 47 & 45 \\
\hline $\begin{array}{l}\text { Gestational } \\
\text { age (weeks) }\end{array}$ & 28 & 27 & 26 \\
\hline $\begin{array}{l}\text { Days on } \\
\text { ventilatot }\end{array}$ & 10 & 15 & 34 \\
\hline $\begin{array}{l}\text { Days on } \\
\text { CPAP }\end{array}$ & 27 & 29 & 47 \\
\hline $\begin{array}{l}\text { Lung } \\
\text { complience }\end{array}$ & 1,0 & 0,7 & 0,6 \\
\hline
\end{tabular}

[Results]

IV/Q matching in three infants. Normal:50\%, 0,6$1,4]$
Conclusion3-D ventilation-perfusion scintegraphy enables a more accurate and functionally oriented severity grading in infants with BPD. Increasing V/Q abnormalities were seen on SPECT with increasing clinical severity grade. SPECT illustrates the regional mismatch between ventilation and perfusion. An inhomogenious distrubution of $V$ and $Q$ even if the $V / Q$ matching is good is a bad prognostic factor according to our findings.

30

\section{DEVELOPING THE PAEDIATRIC INTENSIVE CARE PAIN ASSESSMENT TOOL (PICPAT): A TEAM EFFORT!}

\author{
J. Harris, S. Tibby
}

\section{Paediatric Intensive Care, Guys and St Thomas' NHS Foundation Trust, London, UK}

Aims: A variety of pain assessment scores exist in PICU; however none are used universally, and many also assess sedation. Our aim was to develop an exclusive pain assessment score applicable to all ages of PICU patients, both ventilated and nonventilated.

Methods: Audit of current practice within a 20 bed, multidisciplinary PICU. This was followed by a literature search, and then a series of focus groups with staff. Following this a pain tool was developed via a modified Delphi approach.

Results: The audit revealed (a) that documented pain assessment was often lacking within the clinical notes, and (b) pain scores, when assessed via our current scoring system rarely correlated with analgesics given. The literature search revealed 10 potential candidate scores; all of which were rejected at the focus groups. Reasons included: length of time required to perform, operational definitions being too subjective, and some definitions were not applicable to our patient group (e.g. age specific, non-ventilated). From this, we amalgamated aspects of several scores via the Delphi approach, producing a 4-domain score (Paediatric Intensive Care Pain Assessment Tool: PICPAT) comprising an ordinal scale of 0-8.

Conclusions: The next stage will involve training a core clinical group of nurses for assessment of the scores construct and concurrent validities, and inter-rater agreement. 